\title{
53
}

\section{Introducing spatial information systems into schools: a curriculum project}

\author{
John Oakley \\ Bruce Horton \\ Charles Sturt University \\ Bathurst \\ New South Wales \\ Australia
}

\begin{abstract}
This paper deals with the development of SISIC (Spatial Information Systems in Classrooms) with a pupil friendly interface to complicated Spatial Information Systems (SIS) and associated cadastral and census data, and its integration and use within the Secondary Geography Curriculum at a Technology High School in New South Wales, Australia. The SISIC software developed and used within the project is described and briefly demonstrated. The human, technological and educational aspects of the process of integration of SISIC into the geography curriculum are outlined. Details are given of the SISIC curriculum resource package developed as a result of the project.
\end{abstract}

Main conference themes: information technology, software

Educational areas: secondary education

Study topics: humanities/social sciences, computer literacy

Secondary keywords: curriculum development, database, human computer interface, information handling, technical innovation 


\section{INTRODUCTION}

"It is estimated that approximately $80 \%$ of all data held by government departments has a spatial component" (Australian Institute of Spatial Information Sciences and Technology).

This paper describes a project to integrate powerful Spatial Information System (SIS) software into the curriculum of a secondary school in New South Wales (N. S. W.), Australia. The project involved two academic staff of Charles Sturt University, three secondary social science teachers, the Land Information Centre of N.S.W. (LIC) and the distributors of the SIS software, MapInfo Australia. The N.S.W. Computer Education Group, the Australian Bureau of Statistics (ABS), the Surveying and Mapping Industry Council of N.S.W. The Australian Institute of Spatial Information Sciences and Technology (AISIST), while not directly involved, provided financial support and specialist resources.

The use of SIS in secondary schools has hitherto been difficult, if not impossible due to the sophisticated nature of the software involved, the nonavailability of appropriate digital data and the lack of spatial information system expertise by teachers. These problems were largely resolved as part of this project.

\section{AIMS OF THE PROJECT:}

The aims of the project were to:

- Identify the factors contributing to the success or otherwise of the process of implementing technological innovation at the secondary school level.

- Select SIS software appropriate for major sections of a range of secondary social science curricula.

- Train teachers in its use.

- Develop a user interface which would enable pupils to use the software without having to cope with its complexities and which would minimize the potential for computer based problems.

- Develop a curriculum package comprising SIS software; digitized spatial data and census data for selected areas of N.S.W.; video and other information on SIS and its potential uses; software tutorial; suggestions for teaching/learning activities; sample pupil work books. 


\section{SPATIAL INFORMATION SYSTEMS (SIS)}

A spatial information system can be thought of as a very sophisticated relational database which uses digitized data having a spatial component, such as cadastral data (streets and property boundaries), topographical data, administrative and statistical boundaries, or census data. These data are presented in map layers and/or table format allowing analysis and interpretation. Users are also able to create their own layers and/or add data to existing layers. The power of a computerized SIS is its ability to carry out sophisticated data analyses and to present the results visually as a screen map, table or graph which can then be printed.

The basic digitized cadastral data together with orthophoto and topographical maps, and large aerial photographs were provided by the N.S.W. Land Information Centre (LIC). The software was donated by MapInfo Australia who also gave considerable programming and other resources to stage two of this project. The Australian Bureau of Statistics (ABS) also donated a sample data set for the trialing process.

\section{Method}

The project set out to develop SIS based teaching modules for the Years 7-10 and Years 11-12 geography syllabuses for N.S.W. The first phase of the project focused on local area studies with a Year 7 class, while phase 2 focused on the Year 11 Senior Geography Project (SGP). The SGP involves students carrying out individual projects requiring investigation of a geographically based problem in their local area.

The initial aim of multiple modules was modified in favour of a more generic software interface which could be accessed at different levels and could be used across the total geography curriculum or any other curriculum for which there was available appropriate data, e.g. science and agriculture.

The first major decision related to the software to be used. Two software packages were considered the most appropriate for secondary school use. The social science staff at the school were invited to participate in evaluating these two packages over an extended period including three intensive hands-on inservice days. As a result the staff unanimously decided that the MapInfo package best met their needs. It was also evident at this time that the complex nature of the interface would cause difficulties in a classroom context and would need to be customized for use by children. Fortunately the software allows customization without too many difficulties.

Clarification of the roles of each participant was achieved at a meeting involving all interested parties. At a meeting of the school social science staff three teachers volunteered to represent the whole staff in the development and 
implementation of the modules. These teachers worked with the university participants to further develop their skills and knowledge of the MapInfo package. Joint discussions then took place on which area of the geography curriculum to address. For the first phase a local area study was decided upon and one of the group undertook to implement the first module with his Year 7 class.

\section{Customizing the interface}

Powerful SIS software is by its very nature difficult for busy teachers to master, let alone for their students. This generates a conflict because the software, in order to be powerful and useful to the professional, must have many advanced and complicated features. On the other hand teachers and pupils need an interface structured in such a way as to allow those SIS facilities of most use in a classroom context to be readily accessed without the complications associated with the full range of menu items. To achieve this and yet not oversimplify or lose important aspects of functionality was a challenge for the project team. The full unadjusted set of menus can lead unsophisticated users to make choices which generate many unforeseen difficulties from which they may not recover.

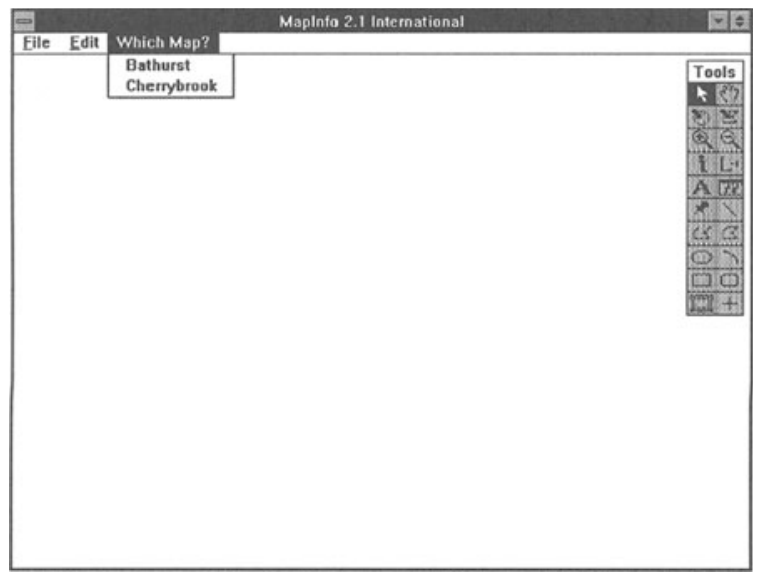

Fig. 1

There are obvious implications for classroom practice. Teachers may not easily be able to achieve their educational objectives as the pupils would be 'fighting' the computer rather that using it as a tool. Under these circumstances continued use of the software is highly unlikely. The interface was customized to allow access only to those functions appropriate to the task 
set and to the stage of the task. The final interface includes the choice to add data to existing layers, to analyze data at two levels of complexity or to access the full functionality of the program via password.

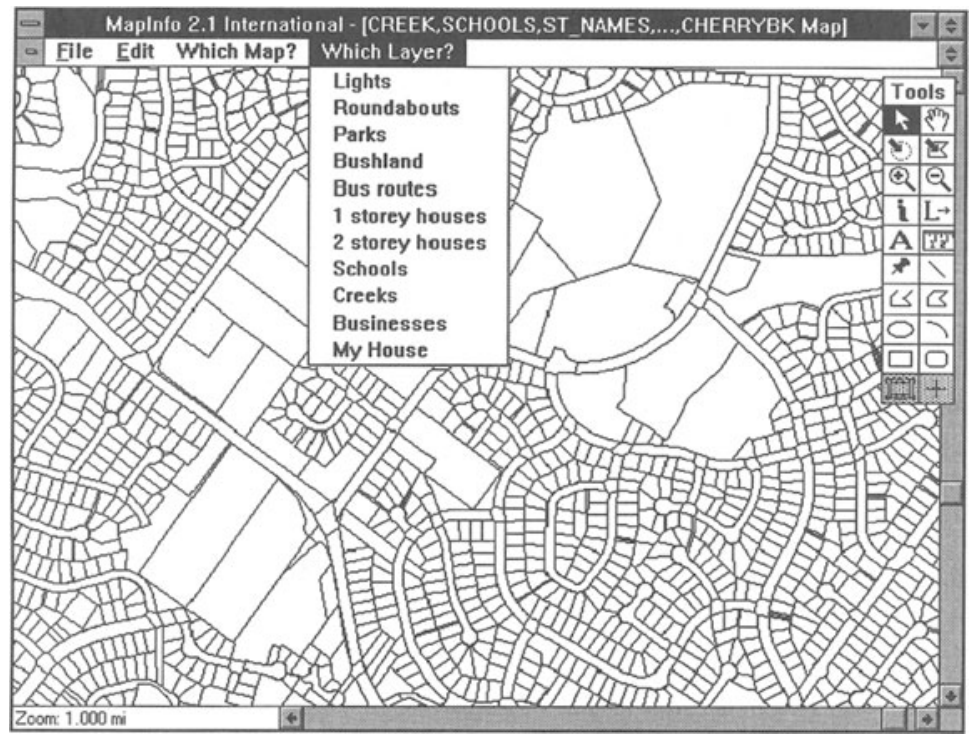

Fig. 2

For phase 1 a special workbook which contained documentation on the use of the software, maps for the field work and educational tasks to be undertaken, was developed for pupil use by the teacher who had volunteered to trial the interface. At all times the other teachers and the university staff were kept informed of progress of the trial. A similar process was followed during the development of phase 2.

Although the bulk of the work was done by the school and university staff, there were regular and reasonably frequent meetings of the other key participants in the project. The fact that the Deputy Surveyor General of N.S.W., the school principal and the most senior executives of MapInfo Australia were active members of the project committee was extremely important as an indication of the project's status and its perceived potential. Of particular significance was the fact that these key members of the project team were in a position within their own organization to allocate the substantial resources necessary for the success of the project.

To maintain momentum for the project the university staff visited the school, initially on a regular weekly basis and then on a fortnightly basis; when 
required at crucial times during the project two or three times per week. This support was seen by the teachers as a crucial factor in the implementation of the project and in the creation and maintenance of their enthusiasm and morale.

The first phase also involved modification of the interface to allow data entry only and was created specifically for students carrying out local area studies (Fig. 1). A work space was created which allowed, by way of software control, the easy selection of a layer upon which to add data (Fig. 2). The menu items available in the data entry mode were minimal.

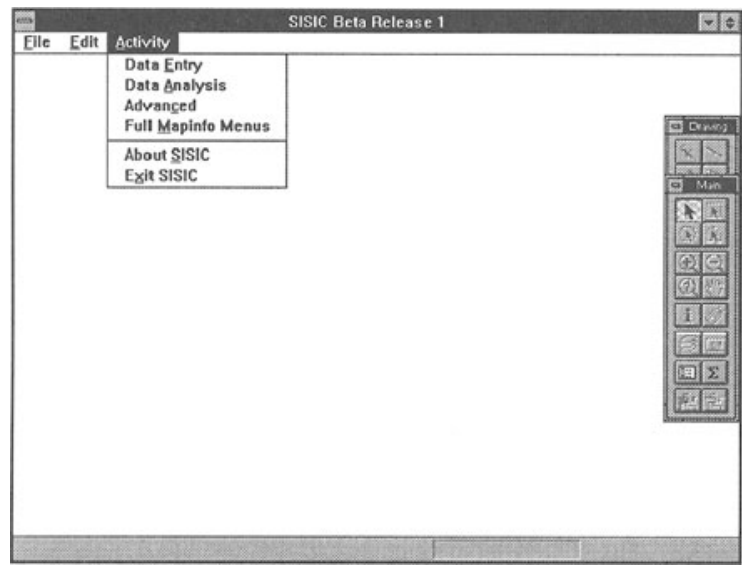

Fig. 3

The second phase involved an extension of the interface to allow research of questions requiring complex analyses of data having a spatial component, principally census data. This phase resulted in second and third levels of complexity (Fig. 3) and additional local government geographical area maps (Fig. 4) being added progressively to the Menu Bar.

The second and third levels of complexity allowed pupils to interact in a 'point and click' manner with a geographical area comprising numerous census collection districts and associated census data. For example a pupil could click to select a number of census collection districts, choose the 'Research' option (Fig. 5), select a method by which the analysis was to be displayed (e.g. choropleth map, table, graph), and a census criterion (or criteria) such as 'Persons Earning Over \$70000' (Fig. 6).

The resulting map(s), graph(s) etc. (Fig. 7) could be manipulated on the screen using a 'Layout' window (Fig. 8) before being printed. For the first time the pupils were able to hypothezise, quickly and easily analyze, and 
evaluate the major categories of Australian census information available for selected local government geographical areas.

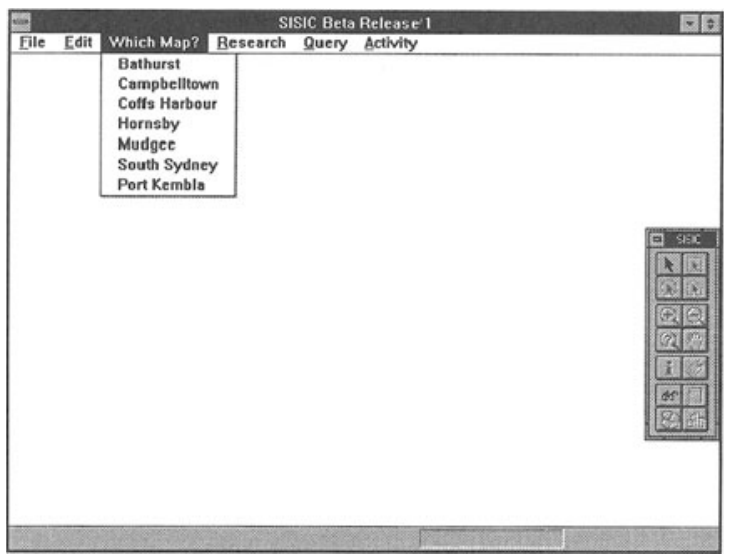

Fig. 4

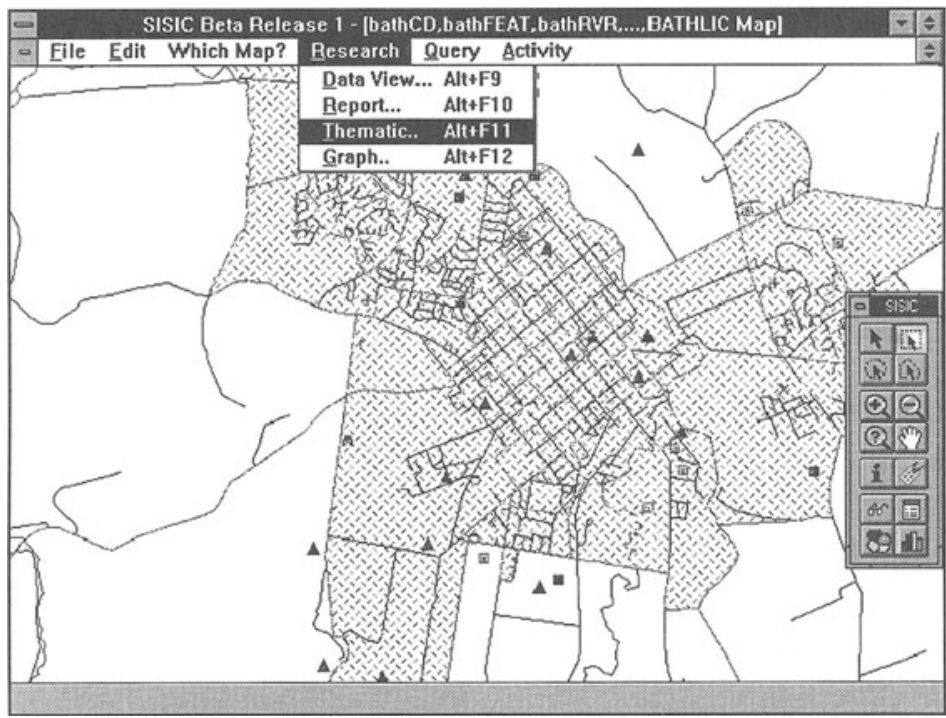

Fig. 5

A successful trial of the data analysis module was carried out with Year 11 students. 


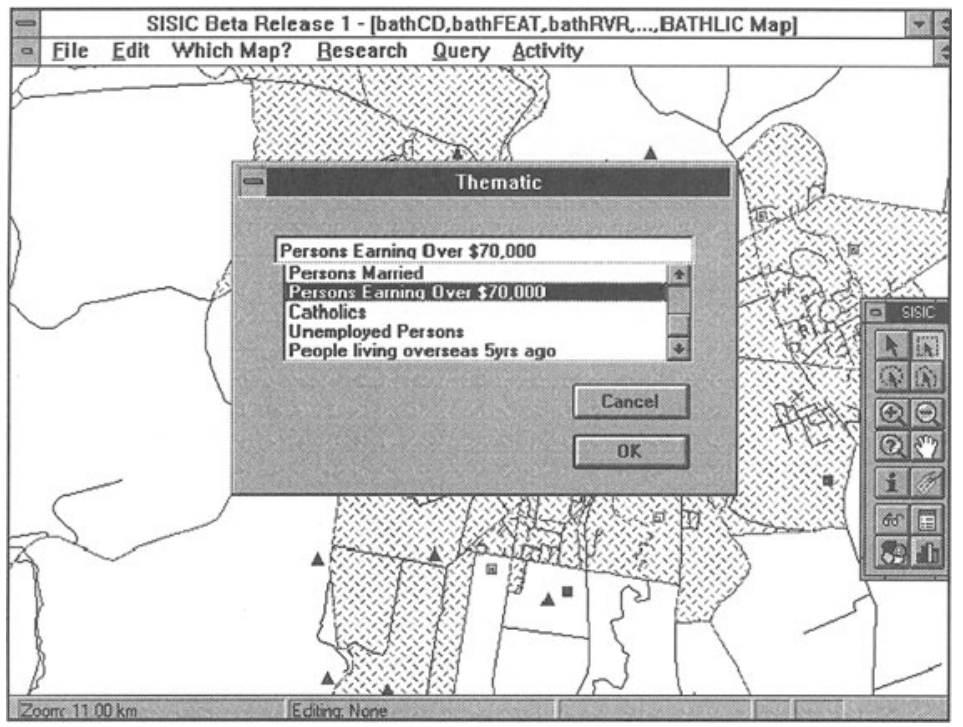

Fig. 6

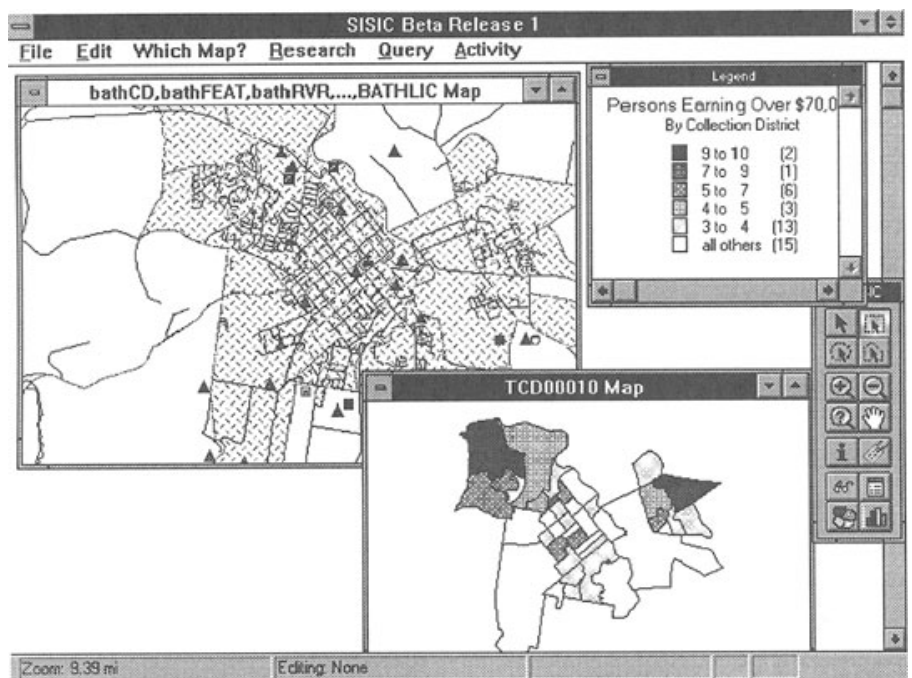

Fig. 7 
The third level of complexity allowed the user to access the full power of the software through password control. This was not trialed as it was an option which was only available to interested and highly competent students.

\section{OUTCOMES}

As a result of phase 1 of this project a Year 7 module on local area studies was developed and trials carried out with a geography class. The module consisted of cadastral data for the school's local area (approximately 150 square kilometres), large aerial photographs and maps of the local area, a student workbook and a modified software interface. The various layers required by pupils were prepared by the project team in readiness for pupils to add data as it was collected.

Phase 2 resulted in a work book to guide students in the use of the extended interface and the analysis of census data. As students were working on a senior geography project as part of their Higher School Certificate studies they were provided with samples of possible analyses of census data. They were expected to be able to decide upon and then analyze data pertinent to their particular project topic.

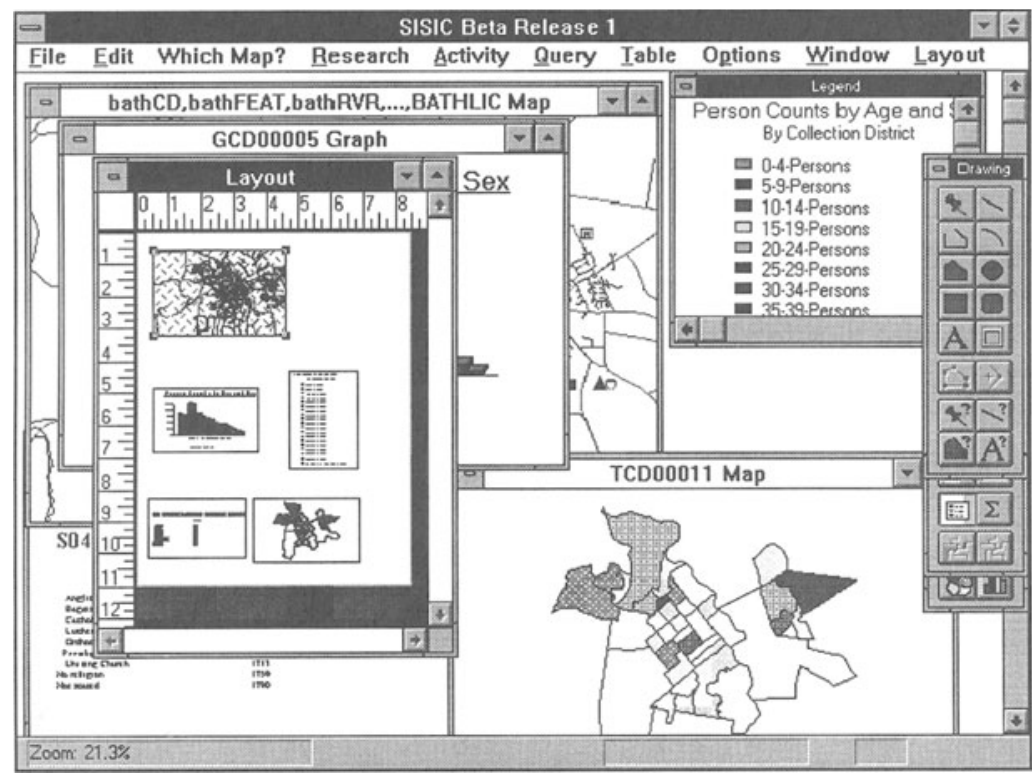

Fig. 8 


\section{EVALUATION}

The evaluation of the project was carried out by means of:

- informal discussion with the teachers;

- questionnaire administered to the teachers;

- written comments and reports from pupils.

The following are examples of comments from the teachers during informal discussions at various times throughout the project.

"When we had the first two days' course I felt overwhelmed, but by taking it slowly, as we have done, I now feel good!"

"The ... project represents an extremely innovative and valuable initiative for all parties involved Students have certainly benefited from the experience of integrating geographical field work with computer software technology. Staff have also been extended in their use of technology in the classroom and have developed strong links with key business and educational institutions."

"(the university staff) have been invaluable partners from start to finish."

Analysis of the responses of teachers to the questionnaire indicated that teachers considered:

- the innovation was feasible and relevant to the improvement of classroom practice;

- they were not being 'manipulated' into participation in the innovation;

- the innovation occurred at a pace which was easily accommodated by teachers;

- there was ongoing support;

- decisions were reached by consensus;

- a sense of 'ownership' was developed.

In the analysis of responses the following factors were identified as contributing to the success of the project:

- team work;

- constant contact between teachers and Charles Sturt University lecturers;

- support of key organizations - Land Information Centre, MapInfo Australia;

- pace which allowed gradual evolution;

- availability of resources within the school;

- project status within the school; 
- keeping the project simple in the early stages.

The following factors were identified as impeding the progress of the project:

- initial uncertainty of funding;

- hardware availability.

The following comments come from written student reports:

"I thought that with the field work it was fun to get out and experience primary data."

"tools on the program .. are simple to use and are basic. I first thought that it would be difficult to use, but it turned out to be simple."

\section{CONCLUSION}

The project culminated in the development of a pupil (and teacher) friendly interface to very complex spatial information system software which allows pupil interaction at varying levels of complexity.

A valuable set of resources has been developed which encourages the gathering and mapping of primary data from the local area and facilitates the analysis of the spatial components of census data in a way not previously possible in a school setting. These resources include inservice training, video and other basic information on geographical information systems, sample teaching programmes and student workbooks, SIS software and tutorial, and a CD-ROM containing sets of sample cadastral and census data for a selection of local government areas within N.S.W.

The curriculum resources are available on a cost coverage, but nonprofit basis for MS-DOS and ultimately Apple Macintosh platforms.

Should these resources prove valuable for N.S.W. schools consideration will be given to extending the data sets for other states in Australia.

\section{REFERENCES}

1. Margolis, H. (1991). Understanding, Facing Resistance to Change. NASSP Bulletin; 75 (537) p. 1.

2. Snider, R. C. (1992). The Machine in the Classroom. Phi Delta Kappan; 74 (4) p. 316. 